\title{
Inflammation versus Oxidative Stress in Pathophysiology of Cognitive Dysfunction induced by Aluminum Chloride in Male Rats
}

\author{
Omyma Galal Ahmed \\ Department of Physiology, \\ Faculty of Medicine, Assiut University, Assiut, EGYPT
}

\begin{abstract}
Alzheimer's disease (AD) is a highly debilitating neurodegenerative disorder characterized by cognitive dysfunction, inflammation and oxidative stress are thought to play major roles in pathophysiology of the $A D$, which of them have a principle role is unclear. The role of brain growth factors, cytokines and oxidative biomarkers in cognitive dysfunction induced by AlCL3 in rats with application of anti-inflammatory (cilostazol) and antioxidant ( $N$-acetyl cysteine, NAC) were investigated to clarify the predominant pathophysiological mechanism involved. Methods: Alzheimer's model group was given AlCL3 $\left(100 \mathrm{mg} / \mathrm{kg}^{-}\right)$orally for 6 weeks. Alzheimer's model + NAC and Alzheimer's model + cilostazol groups were given (NAC) and cilostazol respectively one hr. before AlCL3 for the same duration. Results: anti-inflammatory or antioxidant significantly improved memory retention which was evaluated by Morris Water Maze, passive avoidance task and eight-arm radial maze. This improvement was consistent with histological recovery and was mediated by reduction AlCL3 concentration in the brain hippocampus and frontal cortex, interference with the cholinergic dysfunction as well as prevention of oxidative damage. In addition, anti-inflammatory agent can modulate superiorly the inflammatory response via reduction the levels of inflammatory cytokines and adjustment the levels of brain-derived neurotrophic factors and transforming growth factor B. This finding supports the principal role of inflammation in pathophysiology of $A D$ and suggests the potential therapeutic application of anti-inflammatory agent for this condition. Key words: Brain -derived neurotrophic factors (BDNF); transforming growth factor-B (TGF-B); cognitive function test; AlCL3; Cilostazol; Nacetyl cysteine; inflammatory cytokines and oxidative biomarkers.
\end{abstract}

\section{INTRODUCTION}

Aluminum (Al) is one of the most abundant metals in the earth's crust. $\mathrm{Al}$ and its salts aluminum chloride (AlCL3) are commonly used in daily life, mainly in food products and in drinking water ${ }^{[1]}$. Long-term exposure to $\mathrm{Al}$ has multi-detrimental effects all over the body as dialysis encephalopathy, osteomalacia and microcytic anemia ${ }^{[2]}$. Moreover, numerous studies have observed that concentrations of aluminium are elevated in the brains of patients suffering from Parkinson's disease ${ }^{[3]}$ and senile dementia of Alzheimer's type ${ }^{[4]}$. AlCL3 generates excess free 
radicals and thereby implicates in the etiology of Alzheimer's disease (AD) ${ }^{[5]}$ nevertheless; the core mechanism of Al CL3 damaging effect still debated. Frontal cortex and hippocampus, the areas of the brain important for learning, memory and mood, are highly vulnerable to normal aging and $\mathrm{AD}^{[6]}$.

Anti-inflammatory agent, cilostazol inhibits phosphodiesterase III with therapeutic focus on increasing cAMP that increases the active form of Protein Kinase A, which is directly related to inhibition of platelet aggregation ${ }^{[7]}$. In addition, it has been shown to inhibit lipid peroxidation, apoptosis and neuronal dysfunction in a model of cerebral ischaemia $^{[8]}$. Moreover, cilostazol induced inhibition of inflammatory cytokine release from macrophages ${ }^{[9]}$ and reduced the cell damage caused by oxidative stress ${ }^{[10]}$. However, the ameliorative effect of antiinflammatory agent, cilostazol on the learning and memory impairment has not been studied, and its mechanism is not yet clear.

Several antioxidants are used for therapy of neurodegenerative disorders. Antioxidant agent, $\mathrm{N}$-acetyl cysteine (NAC) is precursor of glutathione that plays an essential role in oxidative damage ${ }^{[11]}$. Also, NAC could attenuate neuroinflammation ${ }^{[\mathbf{1 2}]}$. Based on this finding, the current investigation was designed to evaluate the neuroprotective effect of NAC against aluminium-induced cognitive impairment.Transforming growth factor B (TGF-B) plays an important role in brain response to injurious factors ${ }^{[13]}$. Many studies reported increased TGF-B associated with reduction of brain derived neurotrophic factors (BDNF) in case of cortical dysfunction of AD patients $^{[13]}$.

$\mathrm{AD}$ is the most common form of dementia in elderly people. It affects more than 30 million people worldwide and the number of affected people expected to be double within the next 20 years ${ }^{[14]}$. Therefore, searching the pathophysiological mechanisms underlying in $\mathrm{AD}$ will be an attractive and necessary to identify efficacious strategies that can avoid AD. In this study, we used AlCL3 exposed rat as a model of $\mathrm{AD}$ to examine the pathophysiological mechanisms by which antiinflammatory agent (cilostazol) and antioxidant agent (NAC) exert their effects on learning and memory impairment in order to prove the predominant mechanism involved. Also, the study highlights on the relation between brain growth factors and cytokines and cognitive impairment. By using behavioral tests, biochemical assays and histological study, we compared the effects of anti-inflammatory agent on learning and memory impairment induced by AlCL3 with those of antioxidant agent.

\section{MATERIAL \& METHODS}

\section{Chemicals:}

AlCL3, NAC and cilostazol were obtained from Aldrich Chemicals Co., Sigma Chemicals Co., (St Louis, MO, USA) and Pharmatic Biotech (Sweden) respectively. Their solutions were made freshly at the beginning of each experiment. For oral administration, AlCL3 was dissolved 
in distilled water (DW) while NAC and cilostazol were suspended in $0.5 \%$ carboxymethyl cellulose sodium salt (Aldrich Chemicals Co.).

Animals: Adult male albino rats weighing 100-150 $\mathrm{g}$ at the start of the study were used. They were disease free, obtained and maintained in the Assiut University Animal Nutrition and Care House, and were acclimatized to the laboratory conditions at room temperature before the experiments. The rats were housed in metal cages $(5 / C)$ and they were allowed free access to rodent laboratory food and water throughout the experiment. The housing facility was maintained at $25{ }^{\circ} \mathrm{C}$ with a $12: 00$ $\mathrm{h}$ light, 12:00 $\mathrm{h}$ dark cycle and under a controlled humidity environment. The animals were carried out and all manipulations were done in the light phase between 09.00 a.m. and 04.00 p.m. The experimental protocol was approved by the Institutional Animal Research Committee of Faculty of Medicine, Assiut University, Egypt and was carried out in accordance with the published Guidelines and regulations for the use and care of animals.

Treatment protocols:

The animals were equally alienated into six groups of 10 animals each. In group I (control DW ), II (control antioxidant) and III (control anti-inflammatory), rats were given distilled water orally, $100 \mathrm{mg}$ NAC/ $\mathrm{kg}^{-1}$ b.w./ day IP and $30 \mathrm{mg}$ cilostazol $/ \mathrm{kg}^{-1}$ b.w./ day orally respectively for 6 weeks. Animals of group IV (Alzheimer's model) were given AlCL3 (100 mg/ $\mathrm{kg}^{-1}$ b.w.) through oral gavages for the same duration, while those of group V (Alzheimer's model + antioxidant) and group VI (Alzheimer's model + antiinflammatory) were given the same dose of NAC and cilostazol one $\mathrm{hr}$ before administration of AlCL3 for the same duration. The doses of aluminium chloride, NAC and cilostazol were selected on the basis of those reported in the literatures [15, 16 and 17 respectively]. $\mathrm{AlCl} 3$, NAC and cilostazol solutions were freshly prepared before administration. Drugs were given daily at 08:00 a.m. while behavioral tests were performed at 11:00 a.m.

Methods:

\section{Body weight:}

All animals were weighed at the beginning (baseline) and at the end of the experiment (9 a.m.).

\section{Learning and memory behavioral} tests:

The ability to navigate and complete a maze task requires the ability to create and store a cognitive map, and $\mathrm{AD}$ affects the mechanisms by which visuospatial memory is formed and recalled spatial navigation task. The learning and memory tests were performed at day 0 (before start the experiment) and at day 1, 15, 30 and 45 following AlCL3 administration. The tests include:

A- Morris water maze test (MWM) evaluates spatial learning and memory in rodents [18]. The rats can escape from the water onto the hidden platform after being placed randomly at one of four sites in the pool to test for learning and memory response. Latencies of the four trials /d were recorded and averaged to obtain a measurement 
for the performance of each animal at a given day.

B- Step-down type passive avoidance task: The method used as described by Klenerová et al. ${ }^{[19]}$ Each rat was placed in the illuminated compartment and 10 sec. later the door was raised and the latency (initial latency) to enter the dark compartment was noted and upon entry, the door was closed and a foot shock administered (0.3 m A, $3 \mathrm{~s}$ ), using a shock generator-scrambler; Muromachi-kikai). Twenty-four hours after the training trial (day 1 of ALCL3 administration), the rat was again placed in the illuminated chamber and the latency was again noted up to a maximum of $300 \mathrm{sec}$. (Retention trial). The tests were carried out again at day 15, 30 and 45 of AlCL3 administration to record the onset of memory impairment.

C- Eight-arm radial maze (index of hippocampus-dependent spatial memory). Four fixed arms were baited with food (cheese) in the food plastic cups. Four food pellets were placed just outside the unbaited arms to provide symmetrical food odor all around the maze. After the over night fasting, individual animals were placed in the central area of the maze, timing was begun and the rat was free to discover. Arm choices were recorded after the rat entered completely into the arm and the trial was judged completed when the rat had chosen all baited arms or had spent $10 \mathrm{~min}^{[20]}$. The following parameters were calculated: working memory (the number of repeated entries to baited arms), reference memory (the number of entries to unbaited arms) and completion time (the mean latency required to complete the task).

Biochemical assays:

At the end of the experiment the rats were sacrificed by cervical dislocation, the hippocampus and frontal cortex were micro-dissected, washed in isotonic saline, and dried. Each brain sample was mid-sagittally divided into 2 portions. The first portion was fixed in formalin buffer for histopathological study. The second portion of brain was weighed and homogenized immediately to give $10 \%(\mathrm{w} / \mathrm{v})$ homogenate in ice-cold medium containing $50 \mathrm{mM}$ Tris- $\mathrm{HCl}$ and $300 \mathrm{mM}$ sucrose. The homogenate was centrifuged at 3000 $\mathrm{rpm}$ for $10 \mathrm{~min}$. The supernatant $(10 \%)$ was used for determination of AlCL3 concentration, acetyl cholinesterase activity (AChE), lipid peroxidation and nitric oxide, antioxidant enzyme activities (superoxide dismutase activity, catalase, reduced glutathione, GSH) and Protein estimation. Also, inflammatory cytokines as IL-2, and TNF- $\alpha$ as well as brain growth factors (TGF-B\&BDNF) were estimated in supernatant.

- Lipid peroxidation products were measured in tissue homogenates as described by Aruoma et al., ${ }^{[21]}$.

- Nitric oxide in tissue homogenates was determined by evaluating its oxidation products (nitrates and nitrites) by using Griess reaction $^{[22]}$. 
- Antioxidant enzymes as superoxide dismutase activity (SOD), reduced glutathione and catalase activity in tissue homogenates were assayed by the method of Kono, ${ }^{[23]}$, Ellman, ${ }^{[24]}$ and Luck, ${ }^{[25]}$ respectively.

- Quantitative estimation of total protein concentration in the brain homogenate was carried out according to the method of Gornall et al. ${ }^{[26]}$ to express the concentration of each studied parameter per mg protein.

- Enzyme-linked immunosorbent assays (ELISA) were performed to measure concentrations of TNF-a (Cat. No. KAC 1571), IL2 (Cat. No. M1916), TGF-B (Cat No. KEC 2567) and BDNF (Cat. No. M 1712) by using Biosurce Europe commercial kits with monoclonal antibodies against each substance and according to the manufacturer's protocol. The apparatus used was Ansoth 2000, manufactured in Austria.

- ACh E activity in the brain tissue was measured colorimetrically according to the method of Ellman et al. ${ }^{[27]}$.

- Aluminium concentration was estimated according to the method of Zumkley, ${ }^{[28]}$ by using atomic absorption spectrophotometer. The total concentration of aluminium was calculated in $\mu \mathrm{g} / \mathrm{g}$ of tissue.

Histopathological examination of frontal cortex and hippocampus was done and the sections were stained with hematoxylin and eosin stain $^{[29]}$ then examined by lightmicroscope.

\section{Data analysis:}

Statistical analysis was carried out using Graph Pad Prism software (version 4.03). Data were analyzed non- parametrically (due to the small number of animals in the groups and the cut-off time of latency performance). First, to compare the difference within groups the Friedman analysis of variance (ANOVA) followed by Dunn's method was used. Second, to compare the differences between the control and other group, the Mann/Whitney U-test was used. The level of statistical significance was $\mathrm{P}<0.05$ for all statistical evaluations

\section{RESULT PRESENTATIONS}

Time course monitoring of learning and memory tests of control DW rats revealed that the mean latencies (in sec.) recorded by MWM (Fig. 1 a) and the incidence of errors in both working and reference memory decreased significantly as well as the completion time shortened progressively from day 0 to day 45 (Fig. 2). While retention latencies recorded by step-through passive avoidance at day 1 increased significantly relative to the results of day 0 (Fig. 2 b). Also, biochemical assays of control DW group showed a significant $(\mathrm{P}<0.001)$ increase the levels of LP, catalase, reducedglutathione, TGF-B, BDNF and TNF$\alpha$ while decrease $\operatorname{AChE}(\mathrm{P}<0.05)$ in hippocampus relative to that of frontal area as shown in table 2 and figures $3 \& 4$. In addition, histopathological study showed normal cellular structure of frontal cortex and hippocampus area (H\&E 
$\mathrm{x} 400$ ) which confirms the establishing of normal working and reference memories (Fig. 5, 6). It was observed that administration of antioxidant or anti-inflammatory alone did not significantly influence any of the previous parameters compared to control DW rats.

1) Result of Alzheimer model:

A) On body weight, survival rate and learning and memory tests. Administration of AlCL3 for 45 day significantly reduced body weights, survival rate (table 1) at the end of experiment. Similarly, the latencies recorded by step-through passive avoidance decreased significantly after 15 days with progression until reached maximum at day 45 (figure 1 b). While, it induced a significant increase in the latencies recorded by MWM on day 30 and 45 (Figure 1 a), the number of errors among day 15 , 30 and 45 in working memory and among day 30 and 45 in reference memory. Also, AlCL3 significantly increased the completion time started at day 30 (Fig. 2).

B) On oxidative biomarkers, $\mathrm{ACh} \mathrm{E}$ activity, aluminium concentration, brain growth factors and inflammatory cytokine: Meanwhile, biochemical assays of frontal cortex and hippocampus of Alzheimer model rats revealed a significant increase of lipid peroxidation products, nitrite concentration (Fig.3); AChE activity, the aluminium concentration (Fig. 4); levels of pro-inflammatory cytokines (IL2 and TNF- $\alpha$ ) and TGF-B (table 2) relative to the control DW group. However, Alzheimer model group showed depletion of reduced glutathione levels, superoxide dismutase, catalase (Fig.3) and levels of BDNF (table 2) in both brain areas with obvious effects appeared in hippocampus area.

C) On histopathological study: Gross histopathological changes in frontal cortex and hippocampus, including heavy loss of cortical neurons, lacunae spaces cells and vacuolated cytoplasm were observed in Alzheimer model rats (Fig. 5,6).

2) Effect of application of antioxidant or anti-inflammatory on Alzheimer model rats:

A) On body weight, survival rate and learning and memory tests.

Administration of antioxidant or anti-inflammatory increased significantly the survival rate (table 1), latencies recorded by step-through passive avoidance (Fig. 1 b) at day 30 and 45 with better response in antiinflammatory group than antioxidant their percentage differences from control DW at day 45 were $56 \%$ and $60 \%$ respectively. However, both agents significantly lowered the latencies of MWM (figure 1a), the number of errors of working \& reference memories and the completion time (Fig. 2). Antiinflammatory agent has more amelioration effect than antioxidant and their percentage differences of latencies in MWM from control DW at day 45 were $188 \%, 239 \%$ respectively. The percentage differences from control of antiinflammatory and antioxidant groups in working, reference memories and completion time at day 45 were $169 \%$ $\& 113 \%, 236 \%$ \& $157 \%$ and $130 \%$ \& $123 \%$ respectively. 
B) On oxidative biomarkers, $\mathrm{AChE}$ activity, aluminium concentration, brain growth factors and inflammatory cytokine.

Co-administration of antioxidant or anti-inflammatory agents significantly prohibited the changes in the previously measured parameters (figure 3 \&4). The percent of differences of antioxidant \& antiinflammatory from control DW levels were: (LP $123 \%, 146 \%$ and $106 \%$, $124 \%$ ), (nitrites $105 \%, 123 \%$ and $110 \%, 126 \%$ ), (reduced glutathione $105 \%, 84 \%$ and $75 \%, 55 \%$ ), (SOD $19 \%, 9 \%$ and $19 \%, 5 \%)$ and (Catalase $34 \%, 27 \%$ and $35 \%, 32 \%$ ) in frontal cortex and hippocampus respectively. Similarly, treatment with antioxidant and anti-inflammatory agents significantly attenuated the AChE activity only in hippocampus area and declined the elevated concentration of AlCL3 in both brain areas. (Fig.4). The percent of differences of ACh E from control, in antioxidant and anti- inflammatory groups, were $123 \%$, $149 \%$ in frontal cortex and $122.5 \%$, $100 \%$ in hippocampus respectively while that for aluminum concentration were $110 \%, 103 \%$ in frontal cortex and $149 \%, 140 \%$ in hippocampus respectively. Statistical analysis revealed that administration of antiinflammatory to Alzheimer's model rats reduced significantly the elevated levels of pro-inflammatory cytokines (IL2 and TNF- $\alpha$ ) and TGF-B while it increased levels of BDNF in hippocampus area only (table 2 ).

C) On histopathological study: Remarkable improvement was observed in the anti-inflammatory + Alzheimer's model and antioxidant + Alzheimer's model groups. Normalization of most of neuronal structure was observed after administration of anti-inflammatory agent (Figure 5). Similar changes were observed in hippocampus (figure $6)$.

Table 1: The body weight (grams) and survival rate in different groups of rats.

\begin{tabular}{|c|c|c|c|c|c|c|}
\hline $\begin{array}{l}\text { Body } \\
\text { weight }\end{array}$ & $\begin{array}{l}\text { Control } \\
\text { DW }\end{array}$ & $\begin{array}{l}\text { Control } \\
\text { antioxidant }\end{array}$ & $\begin{array}{l}\text { Control } \\
\text { anti- } \\
\text { inflammatory }\end{array}$ & $\begin{array}{l}\text { Alzheimer } \\
\text { model }\end{array}$ & $\begin{array}{l}\text { Alzheimer + } \\
\text { antioxidant }\end{array}$ & $\begin{array}{l}\text { Alzheimer + } \\
\text { anti- } \\
\text { inflammatory }\end{array}$ \\
\hline $\begin{array}{l}\text { (g) } \\
\text { Initial }\end{array}$ & $\begin{array}{l}138 \pm 3.3 \\
(100 \%)\end{array}$ & $\begin{array}{l}139.2 \pm 3.2 \\
(100 \%)\end{array}$ & $\begin{array}{l}140.4 \pm 2.2 \\
(101 \%)\end{array}$ & $\begin{array}{l}143 \pm 1.8 \\
(103 \%)\end{array}$ & $\begin{array}{l}143.4 \pm 2.1 \\
(104 \%)\end{array}$ & $\begin{array}{l}144.2 \pm 1.8 \\
(105 \%)\end{array}$ \\
\hline $\begin{array}{l}\text { At the } \\
\text { end }\end{array}$ & $\begin{array}{l}198.5 \pm 3.0 \\
(100 \%)\end{array}$ & $\begin{array}{l}195.5 \pm 2.4 \\
(98.5 \%)\end{array}$ & $\begin{array}{l}196.5 \pm 2.8 \\
(99 \%)\end{array}$ & $\begin{array}{l}184.5 \pm 2.6 * * \\
(93 \%)\end{array}$ & $\begin{array}{l}189.1 \pm 1.5 \\
(95 \%)\end{array}$ & $\begin{array}{l}189.3 \pm 1.1 \\
(95 \%)\end{array}$ \\
\hline $\begin{array}{l}\text { Survival } \\
\text { rate } \\
\text { /total }\end{array}$ & $\begin{array}{l}10 \text { of } 10 \\
(100 \%)\end{array}$ & $\begin{array}{l}10 \text { of } 10 \\
(100 \%)\end{array}$ & $\begin{array}{l}10 \text { of } 10 \\
(100 \%)\end{array}$ & $\begin{array}{l}7 \text { of } 10 * * * \\
(70 \%)\end{array}$ & $\begin{array}{l}8 \text { of } 10 \# \\
(80 \%)\end{array}$ & $\begin{array}{l}9 \text { of } 10 \\
(90 \%) \# \# \#\end{array}$ \\
\hline
\end{tabular}

Values represent mean $\pm \mathrm{SE}$ and were analyzed by a $\mathrm{t}$-test $(\mathrm{n}=10$ per group). $* * \mathrm{P}<0.01$, *** $\mathrm{P}<0.001$ relative to control DW, \# $P<0.05$, \# \# \#P<0.010 versus Alzheimer model.). Alzheimer model was induced by AL CL3 (100 mg/kg-1 b.w per rat daily orally) for 45 days. Rats were pretreated with antioxidant (NAC) (Alzheimer's + antioxidant) or anti-inflammatory (cilostazol) $1 \mathrm{hr}$. before AlCL3 for the same duration. $\%=$ percentage difference from control 
Table 2: Effects of antioxidant and anti-inflammatory agents on and brain growth factors and inflammatory cytokines in frontal cortex and hippocampus of Alzheimer model rats.

\begin{tabular}{|c|c|c|c|c|}
\hline \multirow{2}{*}{$\begin{array}{l}\text { Animal } \\
\text { Groups }\end{array}$} & \multicolumn{2}{|c|}{ Brain growth factors } & \multicolumn{2}{|l|}{ Brain cytokines } \\
\hline & $\begin{array}{l}\text { BDNF } \\
\text { (ng/mg } \\
\text { protein) }\end{array}$ & $\begin{array}{l}\text { TGF-B } \\
\text { (pg/mg } \\
\text { protein) }\end{array}$ & $\begin{array}{l}\text { IL-2 } \\
\text { (pg/mg protein) }\end{array}$ & $\begin{array}{l}\text { TNF-a } \\
\text { (pg/mg } \\
\text { protein) }\end{array}$ \\
\hline Frontal cortex & & & & \\
\hline Control DW & $0.35 \pm 0.02$ & $640.2 \pm 2.71$ & $16.07 \pm 0.4$ & $7.53 \pm 0.16$ \\
\hline Control antioxidant & $0.38 \pm 0.02$ & $641.4 \pm 2.69$ & $15.80 \pm 0.31$ & $7.13 \pm 0.23$ \\
\hline Control anti-inflammatory & $0.36 \pm 0.02$ & $644.6 \pm 1.66$ & $15.65 \pm 0.38$ & $7.4 \pm 0.27$ \\
\hline Alzheimer model & $0.23 \pm 0.01 * * *$ & $657.0 \pm 5.25 *$ & $32.70 \pm 0.92 * * *$ & $10.11 \pm 0.55^{* * *}$ \\
\hline Alzheimer's + antioxidant & $\begin{array}{l}0.25 \pm 0.01 \\
(71 \%)\end{array}$ & $\begin{array}{l}654.5 \pm 4.36 \\
(102 \%)\end{array}$ & $\begin{array}{l}31.10 \pm 0.77 \\
(193 \%)\end{array}$ & $\begin{array}{l}9.83 \pm 0.54 \\
(130 \%)\end{array}$ \\
\hline $\begin{array}{l}\text { Alzheimer's + anti- } \\
\text { inflammatory }\end{array}$ & $\begin{array}{l}0.30 \pm 0.02 \\
(86 \%) \# \#\end{array}$ & $\begin{array}{l}656.5 \pm 3.67 \\
(103 \%)\end{array}$ & $\begin{array}{l}27.80 \pm 1.32 \\
(173 \%) \# \#\end{array}$ & $\begin{array}{l}9.16 \pm 0.39 \\
(122 \%)\end{array}$ \\
\hline Hippocampus & & & & \\
\hline Control DW & $0.44 \pm 0.02$ & $742.2 \pm 4.31$ & $15.93 \pm 0.62$ & $10.62 \pm 0.56$ \\
\hline Control antioxidant & $0.44 \pm 0.01$ & $736.2 \pm 3.28$ & $16.30 \pm 0.41$ & $10.63 \pm 0.32$ \\
\hline Control anti-inflammatory & $0.45 \pm 0.02$ & $744.3 \pm 3.512$ & $16.47 \pm 0.50$ & $10.37 \pm 0.47$ \\
\hline Alzheimer model & $0.28 \pm 0.01 * * *$ & $840.5 \pm 3.31 * * *$ & $40.90 \pm 1.30 * * *$ & $20.40 \pm 0.60 * * *$ \\
\hline Alzheimer + antioxidant & $\begin{array}{l}0.31 \pm 0.01 \\
(70 \%)\end{array}$ & $\begin{array}{l}832.4 \pm 2.72 \\
(112 \%)\end{array}$ & $\begin{array}{l}38.60 \pm 1.11 \\
(242 \%)\end{array}$ & $\begin{array}{l}19.10 \pm 0.48 \\
(180 \%)\end{array}$ \\
\hline Alzheimer + anti- & $0.34 \pm 0.02$ & $818.6 \pm 3.01$ & $35.20 \pm 1.26$ & $16.09 \pm 0.54$ \\
\hline
\end{tabular}

Values represent means \pm SEM $(n=10)$. Alzheimer model was induced by AL CL3 (100 mg/kg-1 b.w per rat daily orally) for 45 days. Rats were pretreated with antioxidant (NAC) orally (Alzheimer's + antioxidant) or anti-inflammatory (cilostazol) $1 \mathrm{hr}$. before AlCL3 for the same duration. All parameters were assessed at the end of experiment. Significant levels; ${ }^{*} P<0.05, * * * P<0.001$ versus control DW (Student's $t$-test), \# $P<0.05$,\#\# $P<0.01$, \#\#\# $P<0.001$ versus Alzheimer model group. $\%=$ percentage difference from control. 

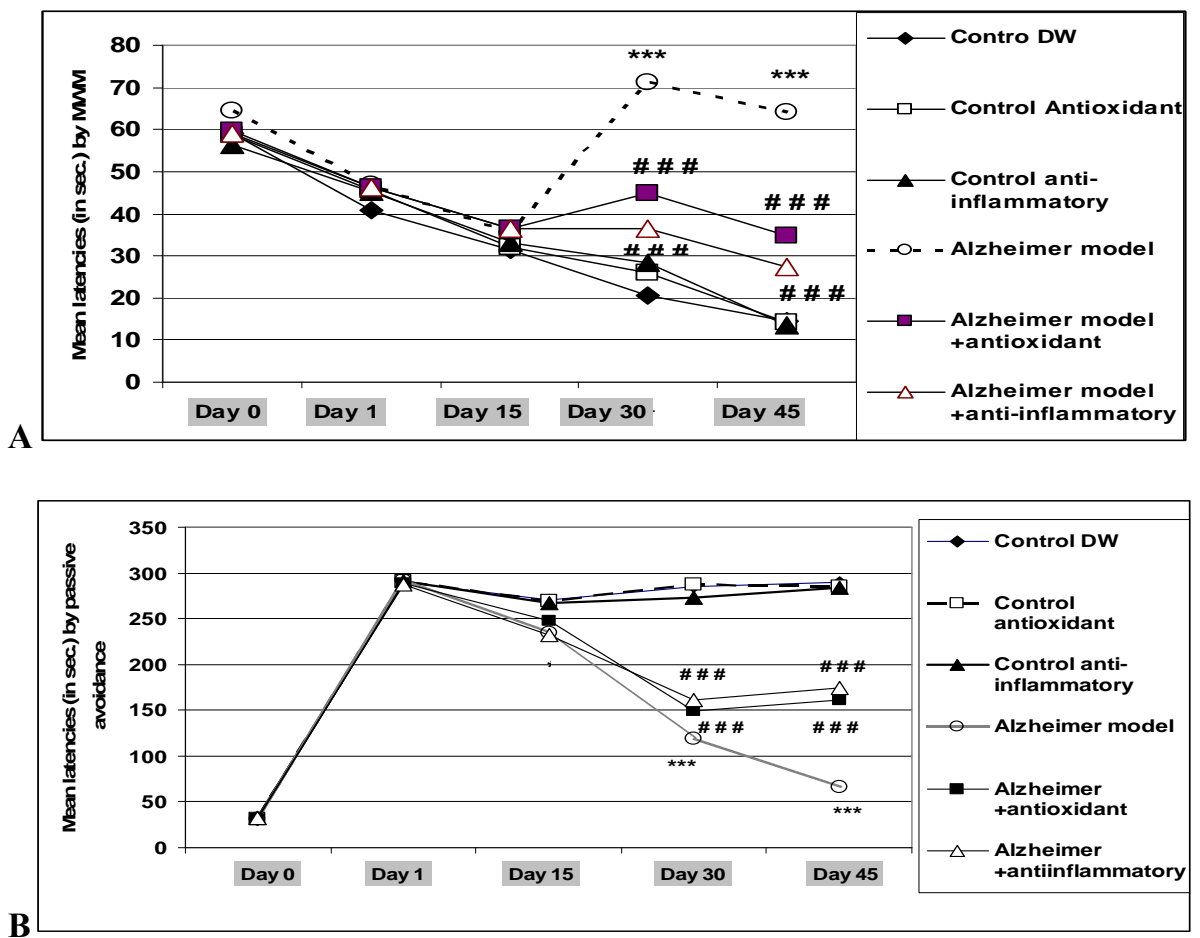

Figure 1: Mean latencies (in sec.) recorded by Morris water maze (MWM) and by passive avoidance in all studied groups. The initial training latencies were measured at day 0 and retention latencies at day 1, 15, 30 and 45 following AlCL3 administration. *P $<0.05$ and $* * * P<0.001$ relative to control $D W$ group. \# \# \#P $<0.001$ relative to Alzheimer model group. Alzheimer model was induced by AL CL3 (100 mg/kg-1 b.w per rat daily orally) for 45 days. Rats were pretreated with antioxidant (NAC) orally (Alzheimer's + antioxidant) or anti-inflammatory (cilostazol) $1 \mathrm{hr}$. before AlCL3 for the same duration. 


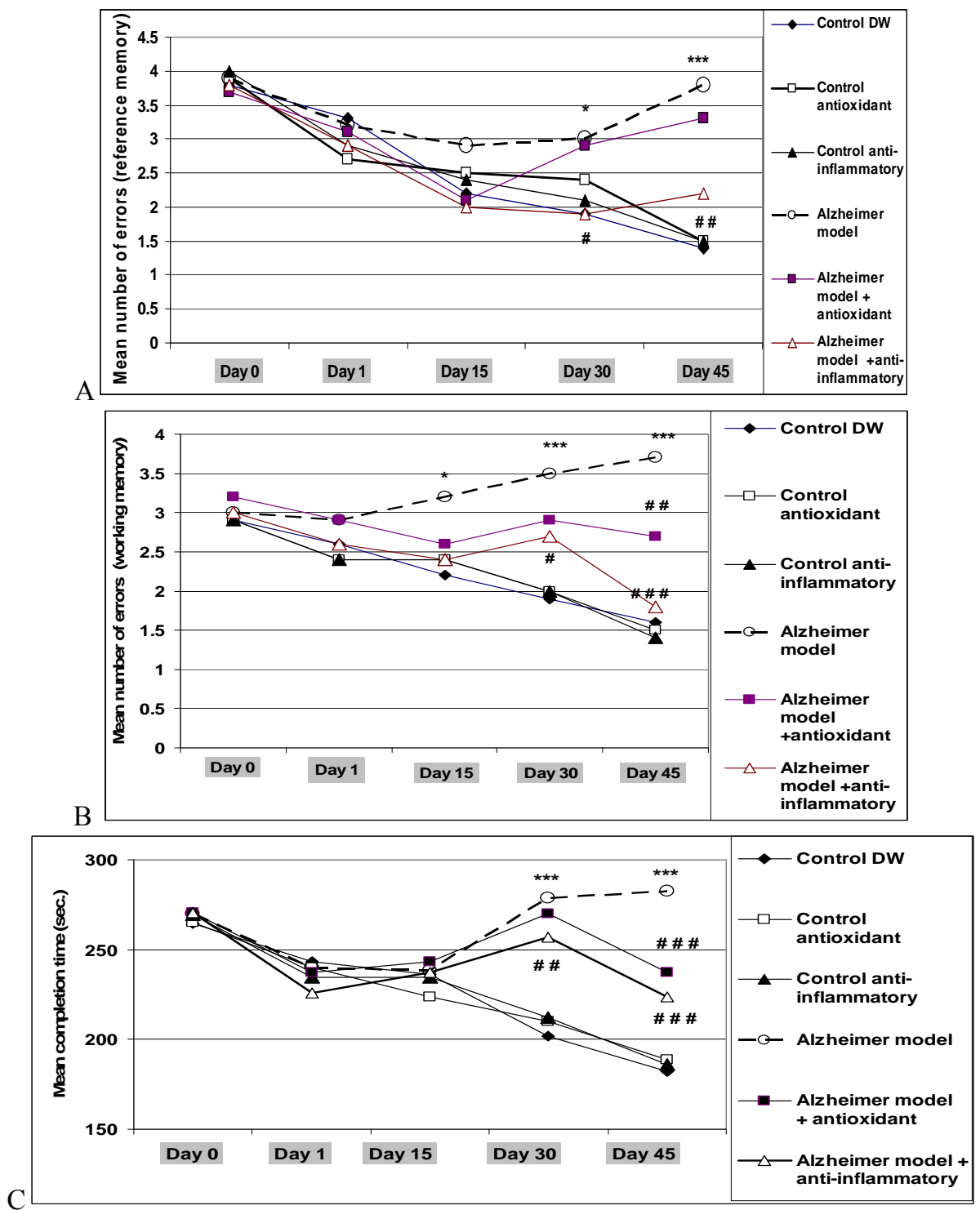

Figure 2: Time course of mean number of errors in measuring working memory (a) \& reference memory (b) and the time required to complete the task in radial arm maze (c). Tests were performed at day $0,1,15,30$ and 45 following AICL3 administration. $* \mathrm{P}<0.05$ and $* * * \mathrm{P}<0.001$ relative to control DW. \#P $<0.05$, \# $\# \mathbf{P}<0.01$ and \# \# \# $<0.001$ relative to Alzheimer model group. Alzheimer model was induced by AL CL3 (100 mg/kg-1 b.w per rat daily orally) for 45 days. Rats were pretreated with antioxidant (NAC) orally (Alzheimer's + antioxidant) or antiinflammatory (cilostazol) $1 \mathrm{hr}$. before AlCL3 for the same duration. 

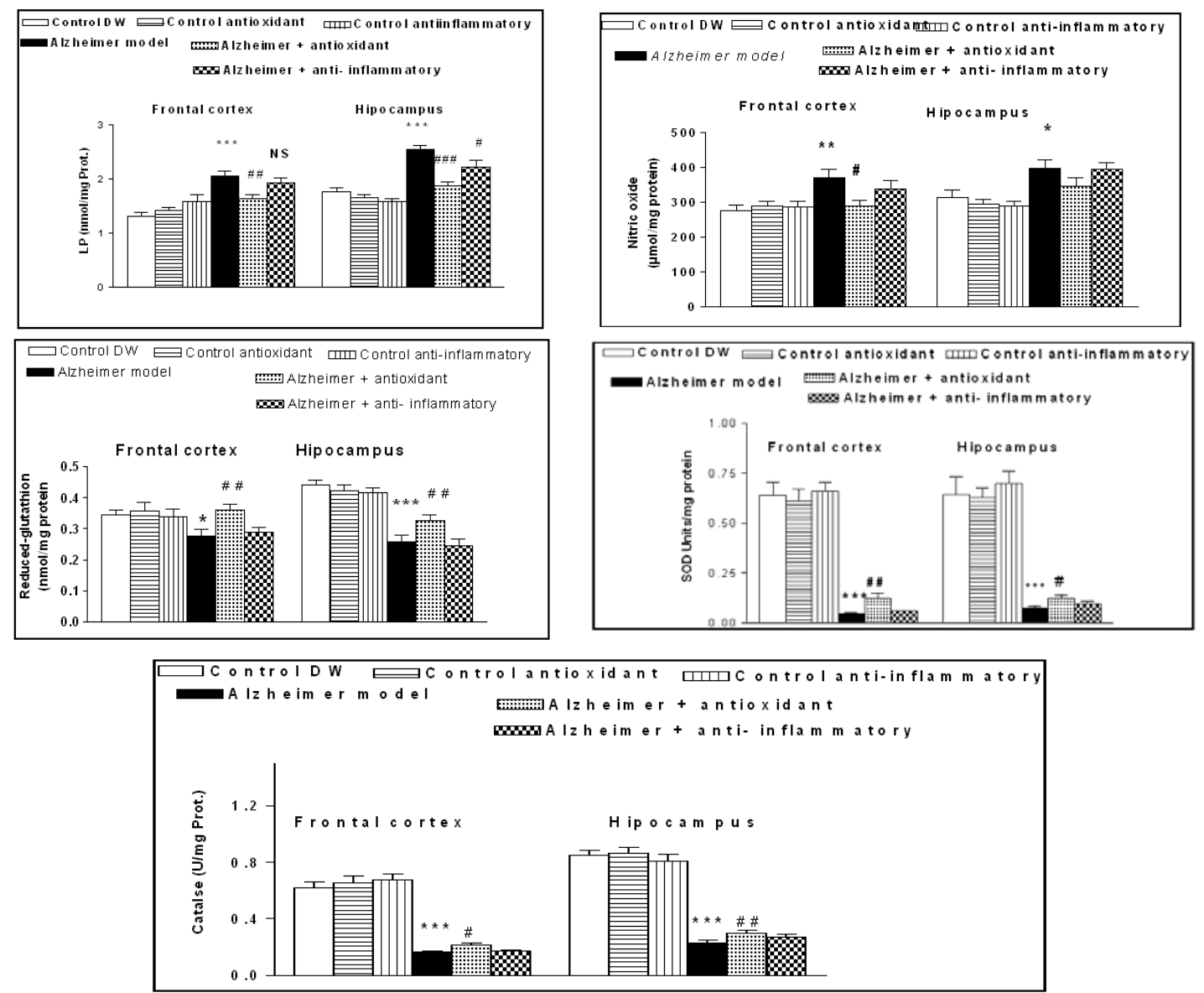

Figure 3: Effects of antioxidant and anti-inflammatory agents on oxidative biomarkers (lipid peroxidation products, nitric oxide, reduced glutathione, Superoxide dismutase, catalase ) in frontal cortex and hippocampus of Alzheimer model rats.

Alzheimer model was induced by AlCL3 (100 mg/kg-1 b.w per rat daily orally) for 45 days. Rats were pretreated with antioxidant (NAC) orally (Alzheimer's + antioxidant) or anti-inflammatory (cilostazol) 1hr. before AlCL3 for the same duration. Values represent means $\pm \operatorname{SEM}(n=10)$. Significant levels; $* * * P$ 

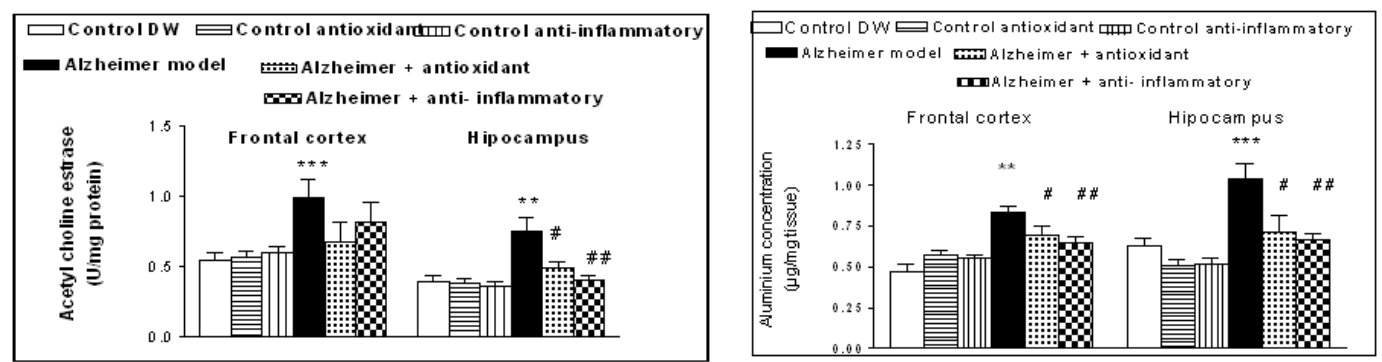

Figure 4: Effects of antioxidant and anti-inflammatory agents on Acetyl choline esterase activity and Aluminun concentration in frontal cortex and hippocampus of Alzheimer model rats. Alzheimer model was induced by AlCL3 (100 mg/kg-1 b.w per rat daily orally) for 45 days Rats were treated with antioxidant orally or anti-inflammatory IP $1 \mathrm{hr}$. before AlCL3 for the same duration. All parameters were assessed at the end of experiment. Values represent means $\pm \operatorname{SEM}(n$ $=10)$. Significant levels; $* * P<\quad 0.01, * * * P \quad 0.001$ versus control (Student's $t$-test), $\# P<0.05$ and \#\# $P<0.01$ versus AlCL3.
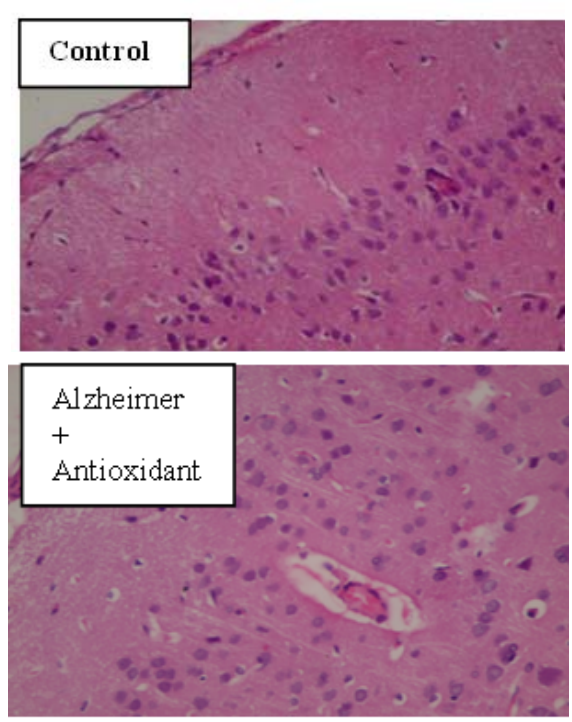
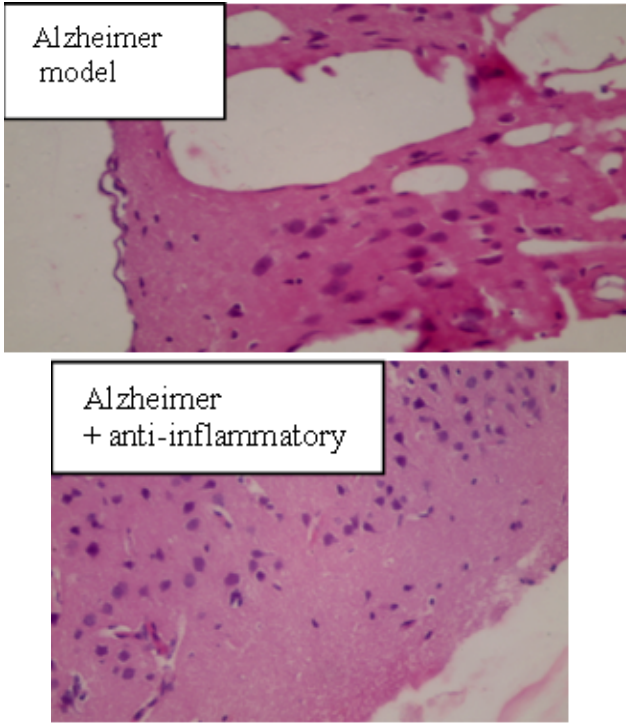

Figure 5: histopathological changes in frontal cortex of Alzheimer model rats showing heavy loss of cortical neurons, lacunae spaces cells and vacuolated cytoplasm were observed in Alzheimer model animals. On the other hand, remarkable improvement was observed in the Alzheimer model rats treated with antioxidant or anti-inflammatory agent. Normalization of most of neuronal structure was observed after application of anti-inflammatory agent. Alzheimer model was induced by AlCL3 (100 mg/kg-1 b.w per rat daily orally) for 45 days Rats were treated with antioxidant orally or anti-inflammatory IP $1 \mathrm{hr}$. before AlCL3 for the same duration. 

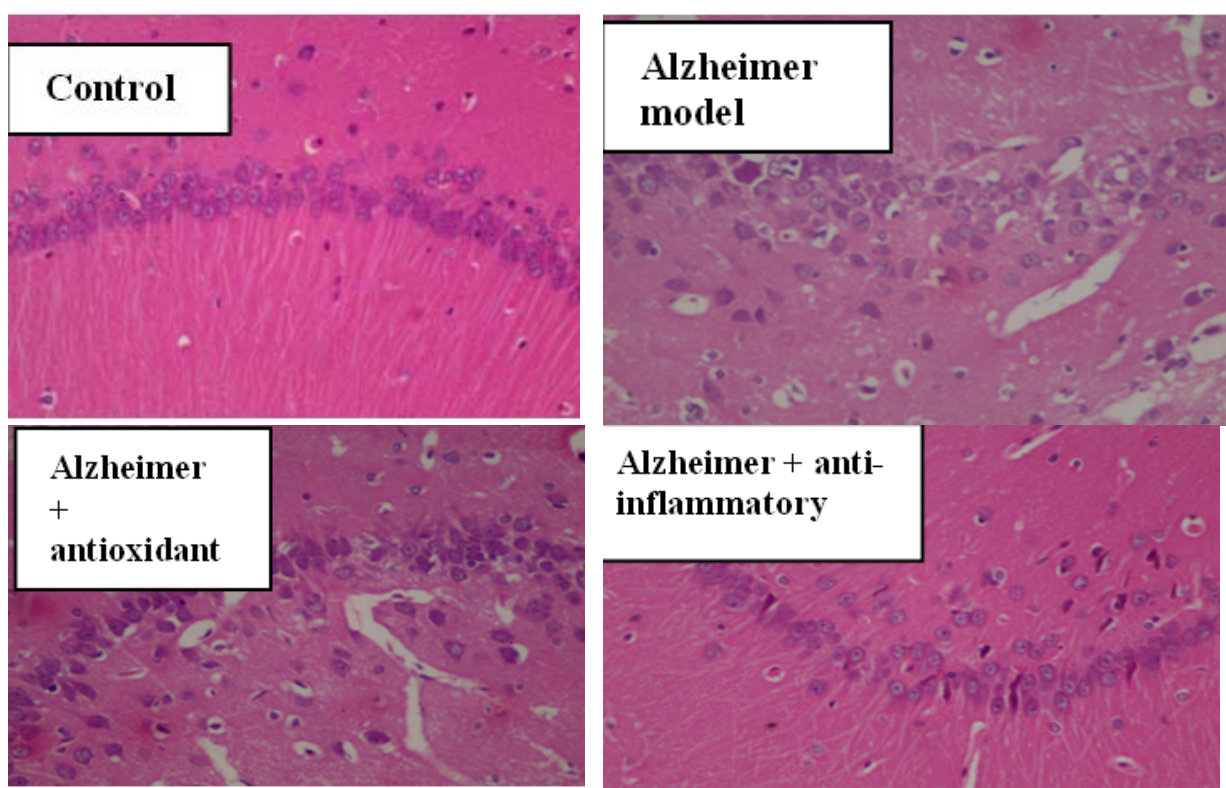

Figure 6: histopathological changes in hippocampus of Alzheimer model rats showing loss of normal structural arrangement of pyramidal cells with frequent appearance of degenerated cells $H \& E \times 400$. Many degenerated pyramidal cells with darkly stained cytoplasm and pyknotic nuclei were still observed after administration of antioxidant agent. Returning the normal arrangement of the layers with recovery of most of neuronal structure were noticed in Alzheimer model treated with anti-inflammatory agent. Alzheimer model was induced by AlCL3 $(100 \mathrm{mg} / \mathrm{kg}-1$ b.w per rat daily orally) for 45 . Rats were treated with antioxidant orally or antiinflammatory IP $1 \mathrm{hr}$. before AlCL3 for the same duration.

\section{DISCUSSION}

In the current study, time course monitoring of memory and learning tests of control animals verifies the development of spatial learning and memory, however, active learning was significantly impaired in Alzheimer's model group which manifested by increasing latencies in MWM associated with increasing reentry frequency of the animals and prolongation of completion time in radial arm maze adding to shorten latencies to enter shocking compartment in passive avoidance. The recorded negative effects of AlCL3 on memory and learning functions, in the current study, concur with the results of Thirunavukkarasu et al., ${ }^{[30]}$. These findings harmonized with marked neuronal loss and vacuolated cytoplasm proofed by histopathological study of frontal cortex and hippocampus of Alzheimer's model rats. These results prove the success of orally administered $100 \mathrm{mg} / \mathrm{kg}$ AlCL3 to 
reach the brain and induce model of $\mathrm{AD}$ with cognitive dysfunction that manifested mostly after thirty days of AlCL3 exposure which is in concordance with the studies of Abdel-Aal et al.. ${ }^{[31]}$ who reported that AlCL3 is considered as a potential etiological factor in AD. This finding could be attributed to the ability of aluminium to interfere with cyclic GMP, involved in long-term potentiation and memory ${ }^{[32]}$ that could explain the recorded memory impairment.

Administration of antioxidant or anti- inflammatory agents to Alzheimer's model animals induced a significant improvement of learning and memory tests with obvious response recorded after antiinflammatory application that goes in lines with the results of Lee et al.., ${ }^{[33]}$. Anti-inflammatory and antioxidant agents began to improve the performance of the Alzheimer model rats at day 30 , which verify their abilities to retain and retrieve information after treatment with both agents. Their amelioration effects on cognitive function supports by previous investigators ${ }^{34435]}$. Antiinflammatory, cilostazol can protect against cognitive impairment induced by hypoperfusion in rats ${ }^{[34]}$ and by intracerebroventricular injection of $\mathrm{A} \beta_{25-35}$ in $\mathrm{C} 57 \mathrm{BL} / 6 \mathrm{~J}$ mice $^{[36]}$ as well as in human patients with $\mathrm{AD}^{[37]}$.

In the current study, Alzheimer's model showed a reduction in body weight and the number of living rats that were associated with deterioration of cognitive function. The physiologic explanation of this outcome may be contributed to the ability of AlCL3 to depress general brain function including appetite centre that runs parallel with suppression of cognitive function [38]. Neither the used antiinflammatory nor antioxidant agent can increase significantly the body weight however; they increased the suppressed survival rate.

Cholinergic neurons are positive markers for the progression of memory so disturbance of acetylcholine and ACh E activity may be one of the mediators of cognitive dysfunction in $\mathrm{AD}^{[39]}$. AlCL3 has a biphasic effect on ACh E activity, with an initial increase in the activity of this enzyme followed by a marked decrease. This biphasic effect has been attributed to the accumulation of aluminium in the brain ${ }^{[40]}$ which coincides with the recorded elevation of AlCL3 concentration that parallel with increasing $\mathrm{ACh} \mathrm{E}$ activity in frontal cortex and hippocampus areas in the current investigation. This finding may be explained by the easy access of AlCL3 to the brain via the specific high affinity receptors in the blood-brain barrier ${ }^{[41]}$. The results presented here showed that antiinflammatory and antioxidant agents were able to attenuate the increased concentration of aluminium and $\mathrm{ACh}$ E activity in both regions of the rats' brain.

The brain is an organ that is in particular more susceptible to peroxide damage. Beside, increased production of reactive oxygen species (ROS) as lipid peroxidation and nitrite concentration, as well as decreased the levels of antioxidant enzymes, in frontal cortex and hippocampus of Alzheimer's model group, may be a vital factor attributed to neuronal 
dysfunction. Thus, it can be hypothesized that oxidative stress could be one of the contributing factors for aluminum induced cognitive dysfunction. Interestingly, the oxidative changes were observed more in hippocampus than frontal cortex that agrees with its fundamental role in the recorded memory impairment. Brain imaging studies confirmed additionally that decreasing brain function in the hippocampus is a main contributor to decline in memory during old age and in $\mathrm{AD}^{[6]}$. Moreover, Zhihao et al., ${ }^{[42]}$ reported that AlCL3 is a potent prooxidant known to enhance lipid peroxides in hippocampus.

Because oxidative stress and cognitive dysfunction are closely related, agents that modulate reactive oxygen species may be potentially protective against impaired memory which is in accordance with the current results as administration of anti-inflammatory and antioxidant was found to improve not only the memory retention but also reduced oxidative damage induced in Alzheimer model. In the present work, antioxidant agent appears to be more potently attenuate the changes in oxidative biomarkers than antiinflammatory. In fact, antioxidant (NAC) is known to increase the intracellular stores of glutathione thereby enhancing the endogenous antioxidant level ${ }^{[43]}$. Also its thiol group interacts directly with reactive oxygen species leading to cellular protection against oxidative damage $^{[11]}$. Furthermore, antiinflammatory, cilostazol inhibits lipid peroxidation and apoptosis in case of cerebral ischaemia $^{[8]}$.
In the present study, exposure of Alzheimer's model rats to AlCL3 increased proinflammatory cytokines (IL2 and TNF- $\alpha$ ) in hippocampus and frontal cortex with obvious effect in hippocampus as AlCL3 activated microglia that induced overproduction of these mediators ${ }^{[44]}$. Also, AlCL3 have been reported to cause cell depletion in the hippocampus ${ }^{[5]}$ thereby induces learning deficits as it may interfere with glutamatergic neurotransmission and impairs hippocampal long-term potentiation, which is a form of synaptic information storage and memory formation $^{[45]}$. Sethi et al., ${ }^{[46]}$ added that AlCL3 impairs various brain functions related to learning and memory.

Therefore, reduction of proinflammatory mediators and controlling microglia activation could attenuate the severity of the memory impairment $^{[47]}$. The present data are in consistent with the results of the current study as anti-inflammatory treatment reduced the elevated levels of proinflammatory cytokines (IL 2 and TNF- $\alpha$ ) especially in hippocampus while co-administration antioxidant, NAC with AlCL3 didn't improve significantly most of the measured proinflammatory cytokines. These results prove the superior role of anti-inflammatory agent which can explain the amelioration that happened in cognitive function and neuronal structure after its administration that harmonize with the findings of Choi et al., ${ }^{[10]}$ and Kim et al., ${ }^{[9]}$.

TGF-B plays a central role in brain response to injury and increases in $\mathrm{AD}^{[13]}$. Findings in the present 
study revealed that exposure of Alzheimer's model rats to AlCL3 caused a significant elevation of TGF$B$ while it reduced the levels of BDNF in frontal cortex and hippocampus with more noticeable effect in hippocampus. This result goes in line with the observation of Tarkowski et al. ${ }^{[48]}$ as they reported increase TGF$\mathrm{B}$ in senile plaque in the brains of $\mathrm{AD}$ patients. Motta et al., ${ }^{[49]}$ suggested that deposition of amyloid plaque (AP) in the brain seem to induce inflammatory cascade that activates microglia to produce excess growth factors and cytokines. The other possible explanation of increasing TGF-B after AlCL3 exposure in the current study was suggested by Zetterberg et al., ${ }^{[50]}$ as TGF-B may increase the clearance of AP by microglia, so it represents a self limiting defense mechanism against further accumulation of AP. Administration of anti-inflammatory agent (cilostazol) to Alzheimer's model animals, in the present study, reduced the high level of TGF-B in hippocampus area. Herein, the decreased hippocampal level of TGFB may propose to be as a result of anti-inflammatory action of cilostazol as it can increase the intracellular cAMP level which inhibits the mitogen-activated protein kinase (MAPK) and interferes with inflammatory cascade and release of cytokines $^{[51]}$.

Nagahara and Tuszynski ${ }^{[52]}$ demonstrated that growth factors strongly influence neuronal survival and function as they have a great efficacy against a variety of pathogenic insults. These findings concur with the present results as antiinflammatory agent, cilostazol significantly raised the reduced BDNF especially in hippocampus. These results go in line with the results reported by other investigators ${ }^{[53 \& 54]}$. Moreover, anti-inflammatory, cilostazol not only modulate inflammatory responses but also affect potently on brain growth factors therefore, it may be a potential therapeutic candidate for the treatment of various inflammatory and neurodegenerative diseases ${ }^{[55 \& 56]}$.

Conclusion, the results from the present study confirm that the selective antioxidant agent (NAC) and anti-inflammatory agent (cilostazol) can ameliorate the memory deficits in Alzheimer's model rats. The improvement of cognitive function may be attributed to the reduction of AlCL3 concentration in the brain hippocampus and frontal cortex, interference with the cholinergic dysfunction as well as the prevention of oxidative damage. In addition, ant inflammatory, cliostazole superiorly can modulate inflammatory response and induce recovery of hippocampal and cortical neurons through adjustment brain growth factors as BDNF and TGF-B. This conclusion supports the predominant role of inflammation and brain growth factors in pathophysiology of $\mathrm{AD}$.

Recommendation: The effects of both agents antioxidant (NAC) and anti-inflammatory, cilostazol need to be simulated in more physiological models of $\mathrm{AD}$, and the involvement of additional molecular mechanism needs to be clarified as DNA fragmentation and an antiapoptotic effect. The shift to clinical trials using therapies that prevent inflammation and generate high levels of growth 
factors should be applied as they will eventually have a useful role in the treatment of AD.

Acknowledgment: This work was supported by the research grant office of the Assiut University Faculty of Medicine. The author wish to thank Professor Amal Taha professors of histology, Histology Departments, Faculty of Medicine, Assiut University, Assiut/ Egypt, for their kind help in histological assessments.

\section{REFERENCES}

1. Yokel $\mathbf{R} A$ and Namara PJ (2001):

Aluminum toxicokinetics: an updated minireview. Pharmacol. Toxicol., 88: 159-167.

2. 2-Becaria A, Bondy SC, Campbell A (2003): Aluminium and copper interact in the promotion of oxidative but not inflammatory events: implications for Alzheimer's disease. JAlz. Dis., 5:31-38.

3. Perl DP, Gajdusek DC, Garruto RM, Yanagihara RT, Gibbs CJ (1982): Intraneuronal aluminium accumulation in amyotrophic lateral sclerosis and parkinsonism-dementia of Guam. Science 217: 1053-1055.

4. Niu $Q$, Yang $Y$, Zhang $Q$, Niu $P$, He S, Di Gioacchino M, Conti P, Boscolo P (2007): The relationship between Bcl-gene expression and learning \& memory impairment in chronic aluminum-exposed rats. Neurotox.. Res., 12: 163-169.

5. Miu $A C$ and Benga $O$ (2006): Aluminium and Alzheimer's disease: a new look. J Alzheimers Dis 10: 179-201.

6. Small SA, Chawla MK, Buonocore M, Rapp PR, Barnes CA (2004): Imaging correlates of brain function in monkeys and rats isolates a hippocampal subregion differentially vulnerable to aging. Proc. Natl. Acad. Sci., USA 101:7181-7186.

7. Taniguchi $\mathrm{K}$, Ohtani $\mathrm{H}$, Ikemoto T, Miki A, Hori S and Sawada Y (October 2007): Possible case of potentiation of the antiplatelet effect of cilostazol by grapefruit juice. J. Clin. Pharm. Ther., 32 (5): 457-459.

8. Watanabe T, Zhang N, Liu M et al., (2006): Cilostazol protects against brain white matter damage and cognitive impairment in a rat model of chronic cerebral hypoperfusion. Stroke 37: 15391545.

9. Kim KY, Shin HK, Choi JM, Hong KW (2002): Inhibition of lipopolysaccharide-induced apoptosis by cilostazol in human umbilical vein endothelial cells. J Pharmacol. Exp. Ther. 300: 709715.

10. Choi JM, Shin HK, Kim KY, Lee JH, Hong KW (2002): Neuroprotective effect of cilostazol against focal cerebral ischemia via antiapoptotic action in rats. J. Pharmacol. Exp. Ther., 300: 787-793.

11. Farr SA, Poon HF, Dogrukol D, Drake J, Banks WA, Eyerman $\mathbf{E}$ et al. (2003): The antioxidants alpha lipoic acid and $\mathrm{N}$ acetylcysteine reverse memory impairment and brain oxidative 
stress in aged SAMP8 mice. J. Neurochem. 84:1173-1178.

12. Khan M, Sekhon B, Jatana M, Giri S, Gilg AG, Sekhon C (2004): Administration of $\mathrm{N}$ acetylcysteine after focal cerebral ischemia protects brain and reduces inflammation in a rat model of experimental stroke. J. Neurosci. Res., 76:519-27.

13. Cacquevel $M$, Lebeurrier $N$, Cheenne $S$ and Vivien D(2004): Cytokines in neuroinflammatory and Alzheimer's disease. Curr. Drug Targets., 5(6):529-534.

14. Zhang $D$, Wang $Y$, Zhou $L$ and Shen D (2011): Multimodal classification of Alzheimer's disease and mild cognitive impairment. NeuroImage 55(3):856-867.

15. Nehru B, Bhalla $P$ and Garg $A$ (2007): Further evidence of centrophenoxine mediated protection in aluminium exposed rats by biochemical and light microscopy analysis. Food Chem. Toxicol., 45:2499- 505.

16. Fu AL, Dong JH and Sun MJ (2006): Protective effect of $\mathrm{N}$ acetyl-L-cysteine on amyloid bpeptide-induced learning and memory deficits in mice. Brain Res., 109:201-6.

17. Masayuki H, Osanao T, Aki N and Hiromasa $M$ (2010): Cilostazol prevents amyloid b peptide25-35-induced memory impairment and oxidative stress in mice. Br. J. Pharmacol., 161: 1899-1912.

18. Morris R (1984). Developments of a water-maze procedure for studying spatial learning in the rat. J. Neurosci. Methods 11: 4760.

19. Klenerová V, Kaminský O, Hliòák Z, Krejèí I and Hy $S$ (2003): Impaired passive avoidance acquisition in Wistar rats after restraint/cold stress and/or stresscopin administration. Gen. Physiol. Biophys., 22: 115120.

20. Olton DS (1987): The radial arm maze as a tool in behavioral pharmacology. Physiol. Behav., 40:793-797.

21. Aruoma $O \mathrm{I}$, Langhton $M \mathrm{~J}$ and Gutteridge J M (1989): The mechanism of initiation of lipid peroxidation. Evidence against a requirement for an iron (II) -iron (III) complex. Biochem. J., 258: $627-620$.

22. Ding $A$, Nathan $C$ and Stuehr $D$ J (1988): Release of reactive nitrogen intermediates and reactive oxygen intermediates from mouse peritoneal macrophages. Comparison of activating cytokines and evidence of independent production. J. Immunol., 141: 2407-2412.

23. Kono Y (1978): Generation of Superoxide radical during autooxidation of hydroxylamine and an assay for superoxide dismutase. Arch. Biochem., Biophys., 186:189-195.

24. Ellman GL (1959): Tissue sulfhydryl groups. Arch. Biochem. Biophys ., 82:4867048677.

25. Luck, H. (1963): Catalase. In: Bergmeyer, H.U. (Ed), Methods of enzymatic Analysis. Academic Press, New York, pp885-888. 
26. Gornall AG, Bardawill CT and David MM (1949):

Determination of serum proteins by means of Biuret reaction. J. Biol. Chem., 177:751-66

27. Ellman GL, Courtney KD, Andres V and Featherstone RM (1961): A new and rapid colorimetric determination of acetyl cholinesterase activity. Biochem. Pharmacol., 7:88-95.

28. Zumkley H, Knoll $O$ and Losse H (1979): $\mathrm{Al}, \mathrm{Zn}$ and $\mathrm{Cu}$ concentrations in plasma in chronic renal insufficiency. Clin. Nephrol., 12: 18-21.

29. Drury, R.B. and Wallington $\mathbf{E}$ A (1980): Carlton's Histological technique. $5^{\text {th }}$ edition. Oxford.; 140-42, 292.

30. Thirunavukkarasu SV, Lokesh $U$ and Venkataraman S (2012): Effect of Manasamitra vatakam, an Ayurvedic Formulation, on Aluminium-Induced

Neurotoxicity in Rats. Trop. J. Pharmaceut. Res., 11 (1): 75-83.

31. Abdel-Aal RA, Assi $A$ and Kostandy B (2011): Rivastigmine reverses aluminuminduced behavioral changes in rats. Eur. J. Pharmacol., 659:16976.

32. Canales JJ, Corbalán R, Montoliu C, Monfort P, Erceg $S$, Hernandez-Viadel $M$ and Felipo V (2001): Aluminium impairs the glutamate-nitric oxide-c GMP pathway in cultured neurons and in rat brain in vivo: molecular mechanisms and implications for neuropathology. J. Inorg. Biochem., 87: 63-69.

33. Lee JH,Park SY,Shin YW,Kim CD,Lee WS and Hong KW
(2007):Concurrent administration of cilostazol with donepezil effectively improves cognitive dysfunction with increased neuroprotection after chronic cerebral hypoperfusion in rats. Brain Res., 1185: 246-255.

34. Lee JH, Park SY, Hong KW, Kim CD, Sung SM, Kim KY and Lee WS (2006): Neuroprotection by cilostazol, a phosphodiesterase type 3 inhibitor, against apoptotic white matter changes in rat after chronic cerebral hypoperfusion. Brain Res., 1082: 182-191.

35. Atish $P$ and Anil $K$ (2009): Effect of N-Acetyl Cysteine against Aluminium-induced Cognitive Dysfunction and Oxidative Damage in Rats. Journal compilation Nordic Pharmacological Society. Basic \& Clinical Pharmacology \& Toxicology 105: 98-104.

36. Park SH, Kim JH, Bae SS, Hong KW, Lee DS, Choi BT and Shin HK (2011): Protective effect of the phosphodiesterase III inhibitor cilostazol on betaamyloid-induced cognitive deficits associated with decreased amyloid $\quad \beta \quad$ accumulation. Biochem. Biophys. Res. Commun., 408: 602-608.

37. Arai $H$ and Takahashi $T$ (2009): A combination therapy of donepezil and cilostazol for patients with moderate Alzheimer disease: pilot follow-up study. Am. J. Geriatr. Psychiatry 17: 353-354.

38. Kowalczyk E, Kopff1 A, and Fijałkowski P (2004): Effect of long-term aluminium chloride 
intoxication on selected biochemical parameters and oxidative- antioxidative balance in experimental animals. Polish Journal of Environmental Studies, 13: 41-43.

39. Bottger $D$, Ullrich $C$ and Humpel C (2010): Monocytes deliver bioactive nerve growth factor through a brain capillary endothelial cell-monolayer in vitro and counteract degeneration of cholinergic neurons. Brain Research 1312:108-119.

40. Kumar S (1998): Biphasic effect of aluminium on cholinergic enzyme of rat brain. Neurosci. Lett 248: 121-123

41. Anil K, Atish $P$ and Samrita $D$ (2011): Neuroprotective effect of carvedilol against aluminium induced toxicity: possible behavioral and biochemical alterations in rats Pharmacological Report 63:915923.

42. Zhihao Wu, Yumei Du, Hua Xue, and Bing Zhou (2012): Aluminum induces neurodegeneration and its toxicity arises from increased iron accumulation and reactive oxygen species (ROS) production. Neurobiology of Aging 33: 199202.

43. Harvey BH, Joubert C, Preez JL, Berk M (2008): Effect of chronic NAcetyl cysteine administration on oxidative status in the presence and absence of induced oxidative stress in rat striatum. Neurochem. Res., 33:508-17.

44. He BP and Strong MJ (2000): A morphological analysis of the motor neuron degeneration and microglial reaction in acute and chronic in vivo aluminum chloride neurotoxicity. J. Chem. Neuroanat., 17(4):207-15.

45. Wang M, Chen JT, Ruan DY, and $\mathrm{Xu} \quad \mathrm{YZ}$ (2002): The influence of developmental period of aluminum exposure on synaptic plasticity in the adult rat dentate gyrus in vivo," Neuroscience 113 (2): 411-419.

46. Sethi P, Jyoti A, Singh R, Hussain $E$ and Sharma $D$ (2008): Aluminium-induced electrophysiological, biochemical and cognitive modifications in the hippocampus of aging rats," NeuroToxicology 29 (6): 10691079.

47. Liu B and Hong JS (2003): Role of microglia in inflammationmediated neurodegenerative diseases: mechanisms and strategies for therapeutic intervention. J. Pharmacol. Exp. Ther., 304: 1-7.

48. Tarkowski E, Issa R, Sjogren M, Wallin $A$ and Kumar $P$ (2002): Increase intrathecal levels of angiogenic factors VEGF and TGF-B1 in Alzheimer disease and vascular dementia. Neurobiology of Aging 23(2):237-243.

49. Motta M, Imbesi R, Rosa MD, Stivala $F$ and Malaguamera $L$ (2007): Altered plasma cytokines levels in Alzheimer disease: correlation with the disease progression. Immunology Letters 114 (1)46-51.

50. Zetterberg $H$, Andreasen $N$ and Blennow K(2004): Increase cerebrospinal fluid levels of 
transforming growth factor-B1 in Alzheimer disease. Neuroscience letters 367(2): 194-196.

51. Tsai CS, Lin FY, Chen YH, Yang TL, Wang HJ, Huang GS et al. (2008): Cilostazol attenuates MCP-1 and MMP-9 expression in vivo in LPS administrated balloon-injured rabbit aorta and in vitro in LPS treated monocytic THP-1 cells. J. Cell Biochem., 103: 54-66

52. Nagahara AH and Tuszynski MH (2007): Growth factors in Alzheimer's disease. Alzheimer's Disease. 26: 257-277.

53. 53- Shin HK, Lee HR, Lee DH, Hong $K$ et al., (2010): Cilostazol enhances neovascularization in the mouse hippocampus after transient forebrain ischemia. $\mathrm{J}$ of neuroscience Research 88:222822212.

54. Tanaka $Y$, Tanaka $R$ and Urabe T (2010): Cilostazol attenuates ischemic brain injury and enhances neurogenesis in the subventricular zone of adult mice after transient focal cerebral ischemia Neuroscience 171: 1367-1376.

55. Dipesh $S \mathbf{P}$, Indermeet $S A$ and Parloop A B (2012): Evaluation of antidepressant and anxiolytic activity of phosphodiesterase 3 inhibitor - Cilostazol. Indian J of Psychological Medicine 34 (2): 124-128.

56. Hye $R$ L, Youn $P$, Hye $Y K$, Won S L, Byung Y R, and Chi D K (2012): Protection by cilostazol against amyloid-b1-40induced suppression of viability and neurite elongation through activation of $\mathrm{CK} 2 \mathrm{a}$ in HT22 mouse hippocampal cells. Journal of Neuroscience Research 90:1566-1576. 
الإلتهاب مقابل الأكسدة في الفيزيولوجيا المرضية للضعف المعرفي المستحث بواسطة كلوريد الألومنيوم في ذكور الفئران

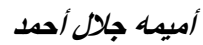 \\ قسم الفسيولوجى ـ كلية الطب جامعة أسيوط
}

مرض الألزهايمر هو انتكساس الخلايـا العصبية الذى يتميز بالخلل المعرفي، ويعتقد أن الإلتهابـات

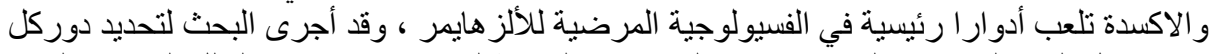

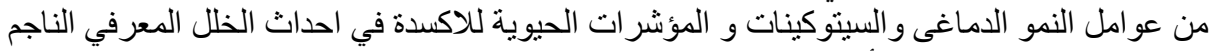

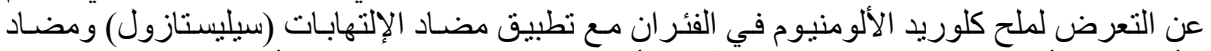

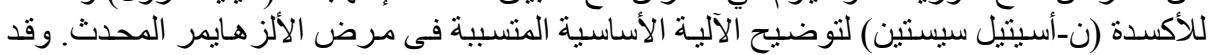

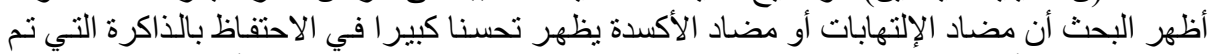

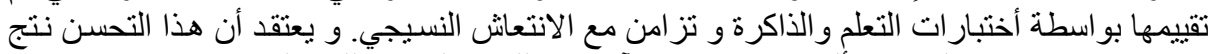

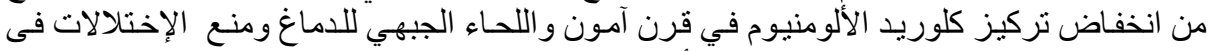

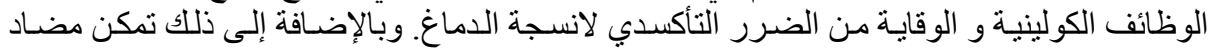

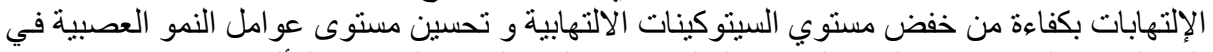

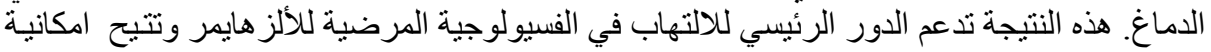

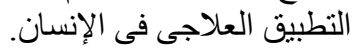

